\title{
Pollinator mediated facilitation and competition determines assembly of Himalayan Rhododendrons
}

\author{
Shweta Basnett ${ }^{1}$, Shivaprakash K N², Robbie Hart ${ }^{3}$, and Soubadra Devy ${ }^{1}$ \\ ${ }^{1}$ Ashoka Trust for Research in Ecology and the Environment \\ ${ }^{2}$ The Nature Conservancy \\ ${ }^{3}$ Missouri Botanical Garden Center for Plant Conservation
}

July 20, 2020

\begin{abstract}
Plant-pollinator interactions are known to structure plant communities at different spatial scales; however, their role in the assembly of plant communities along an elevation gradient is rarely investigated. Here we studied pollinator mediated assembly of nine Rhododendron communities in the Himalayan mountain by using multiple floral traits, pollinators, flowering phenology, and community phylogenetics. Our results suggest that pollinator mediated assembly processes vary across the elevation gradient. In lower elevation Rhododendron communities, the clustered and overdispersed pattern of conserved and labile floral traits, increased flowering overlap, and clustered phylogenetic pattern suggests the joint influence of facilitation/biotic filtering and competition. Whereas in the higher elevation Rhododendron communities, overdispersed floral traits, decreased flowering overlap, and random phylogenetic structure suggests competition as a predominant assembly process. Our study illustrates how the strength of pollinator-mediated facilitation and competition vary in the assembly of plant communities along the elevation gradient.
\end{abstract}

\section{Hosted file}

Manuscript.doc available at https://authorea.com/users/344373/articles/470934-pollinatormediated-facilitation-and-competition-determines-assembly-of-himalayan-rhododendrons 


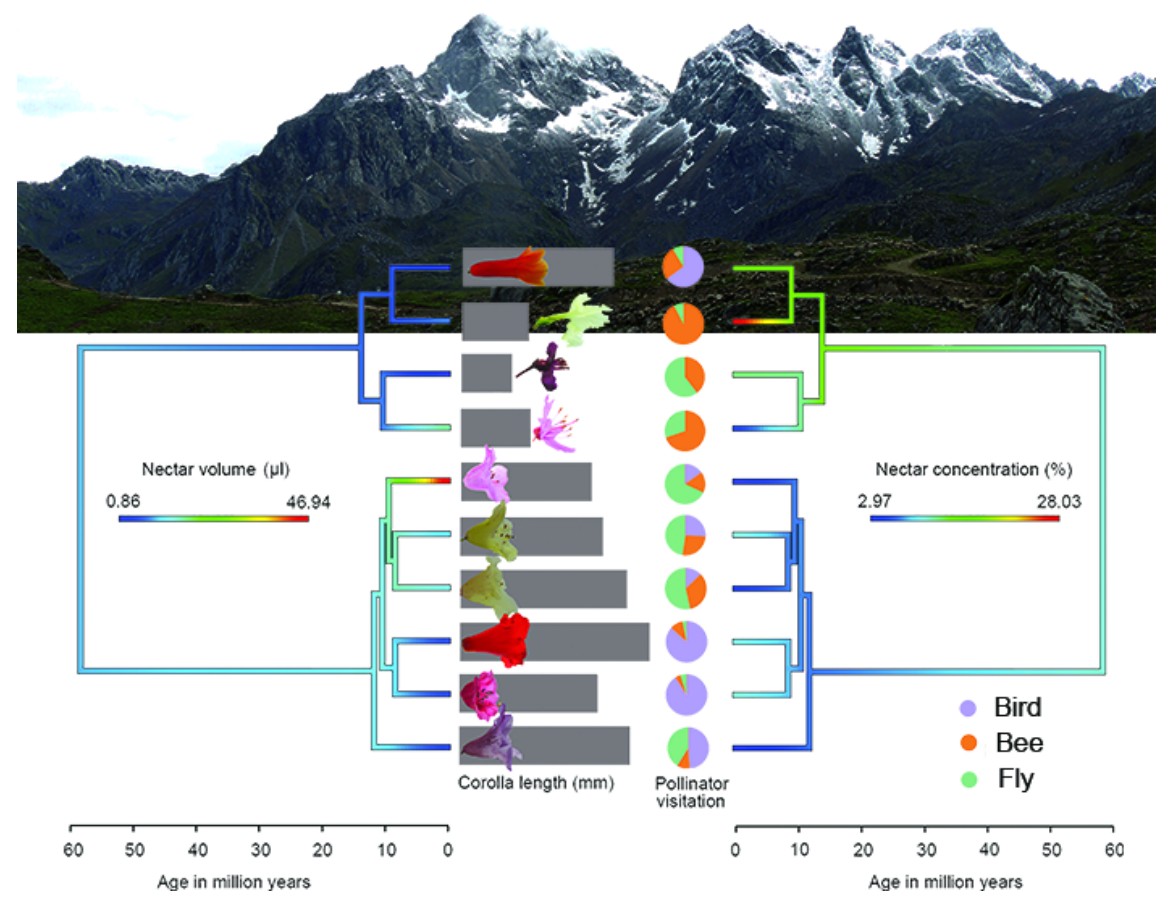

